\title{
Band-gap profiling in amorphous silicon-germanium solar cells
}

\author{
Dietmar Lundszien, ${ }^{\text {a) }}$ Friedhelm Finger, and Heribert Wagner \\ Institute of Photovoltaics, Forschungszentrum Jülich GmbH, D-52425 Jülich, Germany
}

(Received 28 September 2001; accepted for publication 2 January 2002)

\begin{abstract}
Profiled buffer layers at the interfaces of amorphous silicon-germanium $(a-\mathrm{SiGe}: \mathrm{H})$ solar cells are routinely used to avoid band-gap discontinuities and high-defect densities at the $p / i$ and $i / n$ interfaces. It is shown that such profiled $a$-SiGe:H buffer layers can be replaced by a constant band-gap $a$-Si:H buffer, an inverse profiled $a$-SiGe:H buffer, or even a 3-nm-thin $(\delta)$ buffer at some distance away from the interface without losses in the open-circuit voltage $V_{\mathrm{OC}}$ and fill factor while maintaining the same short current density $j_{\mathrm{SC}}$. In view of these results, common model assumptions for $a$-SiGe:H solar cells have to be revised. (c) 2002 American Institute of Physics.
\end{abstract} [DOI: $10.1063 / 1.1456548$ ]

For amorphous silicon ( $a$-Si:H) based stacked solar cells, the classical red absorber is amorphous silicongermanium $(a-\mathrm{SiGe}: \mathrm{H})$, which has a lower optical band gap (depending on the Ge concentration) than compared to $a$-Si:H. These solar cells in $p-i-n$ (or $n-i-p$ ) configuration usually contain $a-\mathrm{Si}: \mathrm{H} p$ and $n$ layers. Consequently, there is a band-gap discontinuity at the $p / i$ and $i / n$ interfaces. Since the defect density of $a$-SiGe:H increases with decreasing optical band gap (i.e., increasing Ge content), one expects a high-defect density at the $p / i$ and $i / n$ interfaces, which will adversely affect the internal electric field and the carrier collection, resulting in poor open-circuit (OC) voltages $V_{\mathrm{OC}}$ and fill factors (FFs). Additionally, in the picture of the so-called defect pool model, the defect density near the interfaces is strongly enhanced due to the position of the Fermi level. ${ }^{1}$ Therefore, considerable effort has been made to counteract these effects by smooth band-gap grading at the interfaces and, in fact, even throughout the entire $a$-SiGe:H absorber layer. $^{2-6}$

In contrast to these concepts, we present an alternative approach where only the band-gap design in the interface region within a distance of $15 \mathrm{~nm}$ to the $p / i$ and $i / n$ interfaces is modified while the intrinsic $a$-SiGe:H absorber layer is kept at a constant band gap $(1.5 \mathrm{eV})$. It will be shown that the profiled $a$-SiGe:H buffer layers at the $p / i$ and $i / n$ interfaces can be replaced by $a$-Si:H buffer layers, or even by an inversely profiled $a$-SiGe:H buffer layer without any loss in $\mathrm{FF}$ and $V_{\mathrm{OC}}$. Furthermore, the influence of the position of a 3-nm-thin buffer layer (with various band gaps) on the solar cell performance is investigated. This leads to surprising insights into the role of interface layers.

All cells were deposited in a multichamber UHV glow discharge system with diode-type electrode configuration and the substrate located at the unpowered electrode (substrate size $100 \mathrm{~cm}^{2} ; 2 \mathrm{~cm}$ electrode spacing). $\mathrm{Si}_{2} \mathrm{H}_{6}, \mathrm{GeH}_{4}$, and $\mathrm{H}_{2}$ are used as process gases. The deposition conditions were: pressure $93 \mathrm{~Pa}$, power density $35 \mathrm{~mW} / \mathrm{cm}^{2}$, substrate temperature $200^{\circ} \mathrm{C}$. All cells were deposited on textured $\mathrm{SnO}_{2}$ (ASAHI, type "U") and had Ag backreflectors. The cell area was $1 \mathrm{~cm}^{2}$. The $a$-SiGe:H $i$ layer in this test cell structure had

${ }^{a)}$ Electronic mail: d.lundszien@fz-juelich.de a constant band gap of $E_{G}=1.5 \mathrm{eV}$. This layer was 54-66 $\mathrm{nm}$ thick and was not optimized to deliver high-current densities. This is not necessary for the present study because the main effects are expected for the $V_{\mathrm{OC}}$ and the $\mathrm{FF}$, and thus a high level of $V_{\mathrm{OC}}$ and $\mathrm{FF}$ as a starting point is required to show the general trends. A-Si:H and profiled $a-\mathrm{SiGe}: \mathrm{H}$ buffer layers with different thicknesses were applied. The band-gap steps were realized by changing the respective gas flows without plasmastop. The gas exchange times are in the order of a few seconds and the resulting nonintentional profilings are in the range of only a few $\AA$ and can be neglected. The details of the interface designs are shown in the following schematic diagrams together with the results. The current density-voltage $(J-V)$ parameters of the cells were measured under red light using a $590 \mathrm{~nm}$ cut-on filter to simulate the light exposure of the bottom cell in a tandem stack.

In a first experiment, we compared cell structures with (a) normally profiled $a$-SiGe:H buffers, (b) $a$-Si:H buffers using various thicknesses for the buffer layers, and (c) inversely profiled $a$-SiGe:H buffers (Fig. 1). In cases (a) and (b), the thickness of the two buffer layers was simultaneously increased from 0 to $12 \mathrm{~nm}$. To achieve similar current densities [short current density (SC)] $j_{\mathrm{SC}}$ for cases (a) and (b),
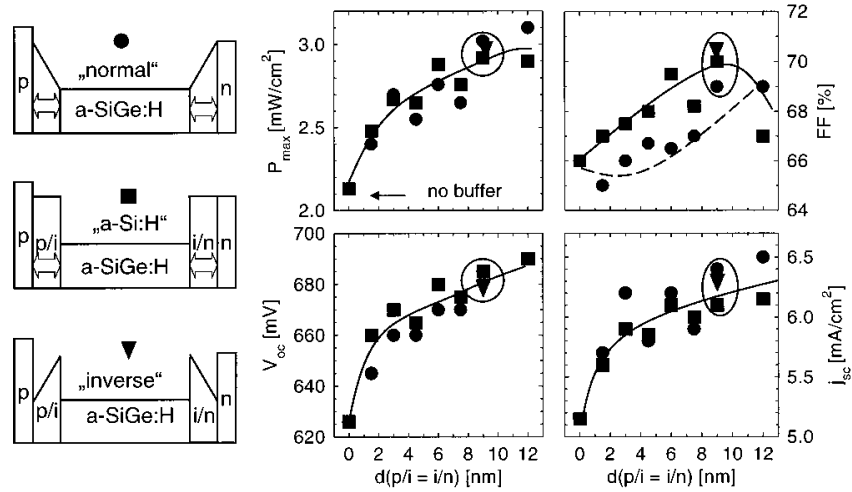

FIG. 1. Comparison between $a$-SiGe:H solar cells with $a$-Si:H buffer layers and the profiled $a-\mathrm{SiGe}: \mathrm{H}$ buffer at the $p / i$ and $i / n$ interfaces. The values for the FF and $V_{\mathrm{OC}}$ are measured as a function of the thickness of the interface layer. $d(p / i)=d(i / n)$. Shown are cells with the $a$-Si:H buffer $(\boldsymbol{\square})$, cells with the normally profiled $a$-SiGe:H buffer $(\bullet)$ and a cell with the inversely profiled $a$-SiGe:H buffer $(\boldsymbol{\nabla})$. 

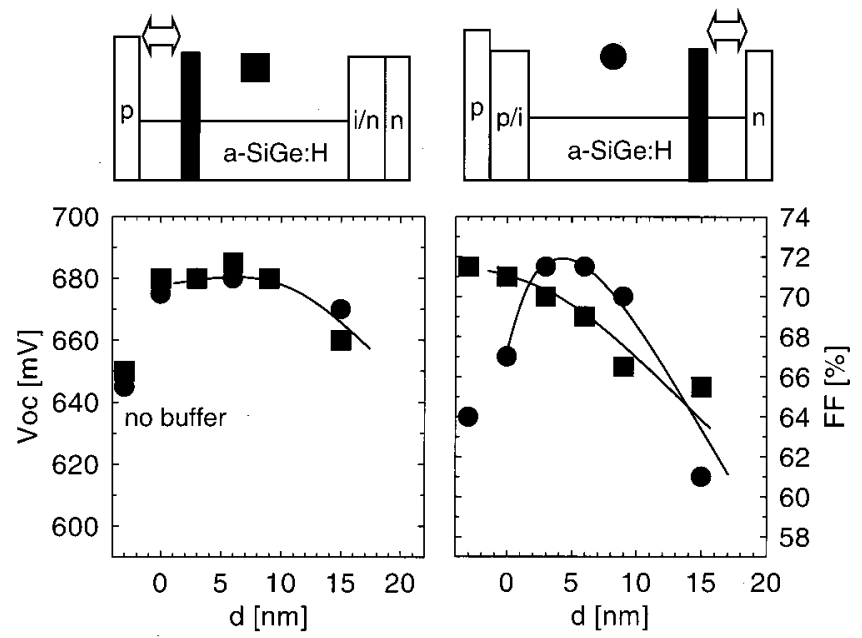

FIG. 2. Influence of a 3-nm-thick $a$-Si:H buffer layer at the $p / i(\mathbf{\square})$ and $i / n$ interfaces (O). The values for the FF and $V_{\mathrm{OC}}$ are measured as a function of position $d$ of the buffer layer with respect to the next doped layer. The optical band gap of the $a-\mathrm{SiGe}: \mathrm{H}$ absorber layer is constant at $1.5 \mathrm{eV}$. Negative values for $d$ indicate no buffer layer.

the $i$-layer thickness had to be adjusted to take care of the increased absorption in the profiled buffer which contains $a-\mathrm{SiGe}: \mathrm{H}$.

The results of the $J-V$ measurements are shown in Fig. 1. We see that adjustment of the $i$-layer thickness between cases (a) and (b) was successful: very similar current densities are obtained for all buffer layer thicknesses. The $V_{\mathrm{OC}}$ shows no difference between profiled and nonprofiled buffer design upon changing the buffer thickness. $V_{\mathrm{OC}}$ increases from $625 \mathrm{mV}$ (without buffer) to $690 \mathrm{mV}$ using a buffer thickness of about $12 \mathrm{~nm}$.

For the FF we observe a pronounced difference. While the FF increases for an $a-\mathrm{Si}: \mathrm{H}$ buffer layer thickness up to $d(p / i)=d(i / n)=10 \mathrm{~nm}$, for the normally profiled $a-\mathrm{SiGe}: \mathrm{H}-$ buffer the FF first remains at a low level up to $3 \mathrm{~nm}$ buffer layer thickness. Between 3 and $10 \mathrm{~nm}$ the FF is nearly $2 \%$ (absolute) higher for the $a$-Si:H buffer compared to the normally profiled $a$-SiGe:H buffer. Above $10 \mathrm{~nm}$ the FF for the cell structure with the $a$-Si:H buffer finally decreases because of the thicker $1.5 \mathrm{eV} a-\mathrm{SiGe}: \mathrm{H} i$ layer necessary to obtain the same $j_{\mathrm{SC}}$. Surprisingly, the band-gap profiling at the $p / i$ and $i / n$ interfaces can be even inverted without any loss in FF and $V_{\mathrm{OC}}$. The performance of such an inversely profiled $a$-SiGe:H buffer [case (c)] is also presented in Fig. 1. In this structure the worst case is realized by applying two band-gap steps, a small band gap $(1.5 \mathrm{eV})$ and an enhanced defect density at both interfaces.

Motivated by these latter results of the inversely profiled $a$-SiGe:H buffers, we investigated how far the position of $a-\mathrm{Si}: \mathrm{H}$ at the beginning (or the end) of the graded $a-\mathrm{SiGe}: \mathrm{H}$ buffer plays a role. This was examined by a very thin $a-\mathrm{Si}: \mathrm{H}$ buffer (of only $3 \mathrm{~nm}$ thickness), which is built in at various positions. The distance $d$ between the thin $a$-Si:H buffer and the doped layer at the $p / i(i / n)$ interface was varied, keeping the $a$-Si:H buffer thickness at the $i / n(p / i)$ constant at $9 \mathrm{~nm}$. Figure 2 shows $V_{\mathrm{OC}}$ and FF as a function of distance $d$ between the doped and the $a$-Si:H layers. $V_{\mathrm{OC}}$ behaves very similar upon variation of distance $d$ at both interfaces. $V_{\mathrm{OC}}$ remains unchanged upon a shift of the $a-\mathrm{Si}: \mathrm{H}$ buffer away

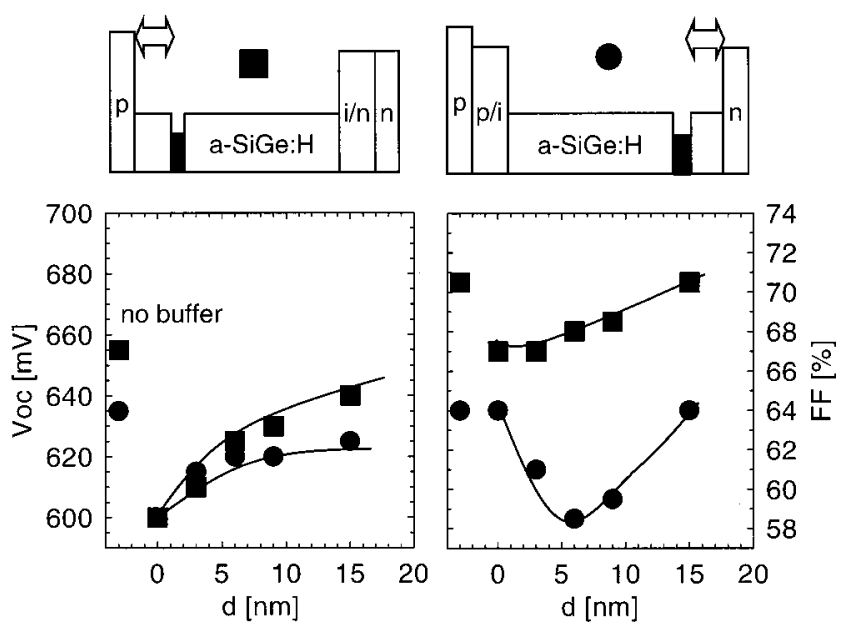

FIG. 3. Influence of a 3-nm-thick $a$-SiGe:H buffer layer $(1.4 \mathrm{eV})$ at the $p / i$ (ם) and $i / n$ interfaces $(\mathbf{O})$. The values for the FF and $V_{\mathrm{OC}}$ are measured as a function of position $d$ of the buffer layer with respect to the next doped layer. The optical band gap of the $a-\mathrm{SiGe}: \mathrm{H}$ absorber layer is constant at 1.5 eV. Negative values for $d$ indicate no buffer layer.

from the doped layer up to a distance of $d=9 \mathrm{~nm}$. Above this distance $V_{\mathrm{OC}}$ decreases. Already with this thin $a$-Si:H buffer at the interfaces $V_{\mathrm{OC}}$ is considerably enhanced compared to no buffer.

For the FF, however, remarkable differences are found for the variation of distance $d$ at the $p / i$ and $i / n$ interfaces, respectively. Without the $a-\mathrm{Si}: \mathrm{H}$ buffer at the $p / i$ interface $\mathrm{FF}$ is high. Introducing a thin $(3 \mathrm{~nm}) a$-Si:H buffer at the interface $(d=0)$ already reduces the FF (Fig. 2) and the FF decreases further upon increasing distance $d$. On the other hand, at the $i / n$ interface without the $a-\mathrm{Si}: \mathrm{H}$ buffer or with an $a$-Si:H buffer directly at the interface $(d=0)$ the FF is on a low level (Fig. 2). Surprisingly, the FF increases if the thin $a$-Si:H buffer is shifted away from the $n$ layer. For $3 \mathrm{~nm}$ $<d<6 \mathrm{~nm}$ the $\mathrm{FF}$ reaches a maximum and decreases again for $d>6 \mathrm{~nm}$.

It thus appears as if positions $d$ from the interface at which the $a$-SiGe:H solar cell is most susceptible to changes of the buffer layer is different for the $p / i$ and $i / n$ interfaces, respectively. While at the $p / i$ interface $\mathrm{FF}$ is already high without an $a$-Si:H buffer [and cannot be further increased by increasing the buffer thickness at the interface (not shown here)], at the $i / n$ interface a position of $d=6 \mathrm{~nm}$ away from the $n$ layer is the most critical position which needs implementation of an $a$-Si:H buffer layer. This is also confirmed in the following where we have replaced the $a$-Si:H buffer of the above experiment (Fig. 2) by an $a$-SiGe:H buffer with a band gap of only $1.4 \mathrm{eV}$ (Fig. 3). Again, distance $d$ between the thin $a$-SiGe:H buffer and the doped layer at the $p / i(i / n)$ interface was varied, keeping the $a$-Si:H buffer thickness at the opposide $i / n(p / i)$ interface constant at $9 \mathrm{~nm}$. In Fig. 3 $\mathrm{FF}$ and $V_{\mathrm{OC}}$ as a function of distance $d$ between the doped layer and the $a$-SiGe:H layer are shown. Again, $V_{\mathrm{OC}}$ behaves similar upon variation of distance $d$ between the doped layer and the thin $a$-SiGe:H buffer on either interface side. For this case $V_{\mathrm{OC}}$ exhibits its lowest value for an $a$-SiGe:H buffer located at the interface $(d=0 \mathrm{~nm})$. Above this distance it recovers again to $V_{\mathrm{OC}}$ values obtained without any buffer at the interface.

For the FF, again, remarkable differences are found for license or copyright, see http://apl.aip.org/apl/copyright.jsp 
the variation of distance $d$ at the $p / i$ and $i / n$ interfaces, respectively. A minimum in the FF is observed using a $3 \mathrm{~nm}$ $a$-SiGe: $\mathrm{H}$ buffer layer $(1.4 \mathrm{eV})$ at the $p / i$ interface $(d$ $=0 \mathrm{~nm}$ ). Upon increasing distance $d$ between the $p$ layer and the $a$-SiGe:H buffer the FF recovers to the value with no buffer at the $p / i$ interface. Again, at a distance $d=6 \mathrm{~nm}$ from the $i / n$ interface the influence of the buffer is most pronounced, but this time a minimum in the FF is found at this position.

The results show that different designs of the interface region like the simple $a$-Si:H and normally or inversely profiled $a$-SiGe:H buffers yield nearly the same performance once the interface layer thickness exceeds a certain value. In particular, $V_{\mathrm{OC}}$ and the FF reach the same high level for any of the applied buffers. It can be concluded that band-gap profiling near the interface does not play an important role, a simple $a$-Si:H buffer is sufficient.

The results obtained with the very thin $a$-Si:H buffer at various positions near the interface could be the "key" structures to explain the experimental results for inverse band-gap profiling. Because there is no beneficial effect of the bandgap profiling itself, it is possible that $a-\mathrm{Si}: \mathrm{H}$ in the inverse profiled $a$-SiGe:H buffer at the $i / n$ interface is responsible for the high FF values. This is supported by the results presented in Fig. 2 for the thin $a$-Si:H buffer.

The results with thin buffer layers in Figs. 2 and 3 show that the solar cell performance ( $\mathrm{FF}$ and $V_{\mathrm{OC}}$ ) exhibits a very pronounced dependence on (a) the side ( $p$ or $n$ side) where the buffer is located, (b) the position of the buffer layer relative to the doped layers, and (c) the optical band gap of the 3 -nm-thick buffer ( 1.8 or $1.4 \mathrm{eV})$. It is remarkable in this context that such a big difference in the $\mathrm{FF}(\Delta \mathrm{FF}=12 \%)$ is observed at a position $d=6 \mathrm{~nm}$ from the $i / n$ interface using different optical band gaps. While $V_{\mathrm{OC}}$ shows the same trends for both the $p$ and $n$ side, the FF has a more complex behavior. The reason for this behavior is not known at this point and should be a challenge for device simulations.
In summary, it was shown that profiled $a$-SiGe:H buffers as an interface layer in $a$-SiGe:H solar cells can be replaced by simple $a$-Si:H buffer layers without any drawbacks in solar cell performance and, surprisingly, an inverse profiled $a$-SiGe:H buffer works also very well. More insight is gained by a series of test cells with 3-nm-thick buffer layers at various distances from the $p / i$ and $i / n$ interfaces, respectively. These cells show that no buffer is necessary at the $p / i$ interface, while a buffer at the $i / n$ interface is important for solar cell performance. Here, the distance from the $i / n$ interface plays a crucial role and is most effective $6 \mathrm{~nm}$ away from the interface (in our case). The difference between the $p$ and $n$ sides mainly shows up in the behavior of the FF, while $V_{\mathrm{OC}}$ behaves similarly in both cases. The experiments lead to a critical discussion of the widely used design concepts of band-gap graded $p / i$ and $i / n$ interface layers. This should lead to a revision of these concepts and a deeper understanding of $a$-SiGe:H solar cells.

This work was supported by the ASE GmbH, Division Phototronics. The authors thank A. Lambertz, F. Birmans, and S. Michel for technical assistance and J. Müller and B. Rech for helpful discussions.

${ }^{1}$ J. Zimmer, H. Stiebig, and H. Wagner, J. Appl. Phys. 84, 611 (1998).

${ }^{2}$ S. Guha, J. Jang, A. Pawlikiewitz, T. Glatfelder, R. Ross, and S. R. Ovshinsky, Appl. Phys. Lett. 54, 2330 (1989).

${ }^{3}$ E. Maruyama, A. Terakawa, K. Sayama, K. Ninomiya, H. Tarui, S. Tsuda, S. Nakano, and Y. Kuwano, Proceedings of the 23rd IEEE PV Specialists Conference, Louisville, KY (1993), p. 827.

${ }^{4}$ J. Fölsch, H. Stiebig, F. Finger, B. Rech, D. Lundszien, A. Lambertz, and $\mathrm{H}$. Wagner, Proceedings of the 25th IEEE PV Specialists Conference, Washington, DC (1996), p. 1133.

${ }^{5}$ R. A. C. M. M. van Swaaij, M. Zeman, S. Arnoult, and J. W. Metselaar, Proceedings of the 28th IEEE PV Specialists Conference, Anchorage (2000), p. 869.

${ }^{6}$ Y. Nakata, H. Sannomiya, S. Moriukchi, A. Yokata, Y. Inoue, M. Itoh, and H. Itoh, Mater. Res. Soc. Symp. Proc. 192, 15 (1990). 